\title{
Anomalous Anodic Dissolution of Aluminum
}

\author{
Go Okamoto,* Takashi Morozumi* and Fukashi AraI*
}

1. Introduction: An anomalous phenomenon in the anodic dissolution of aluminum was first reported as far back as about 100 years by Wöhler and Buff, who noted that hydrogen was evolved at the anode and the weight loss was always larger than that expected by Faraday's law.

At present, there are two antagonistic theories explaining this anomaly: theory of formation of mono-valent $\mathrm{Al}$ ion recently developed by Davidson et al.(1) and theory of self-corrosion proposed by Tomashov $^{(2)}$ and others. ${ }^{(3)}$ The former postulates that the formation of both monovalent and trivalent aluminum ion occurs simultaneously during the electrolysis and the hydrogen evolved is a reaction product between monovalent ion and water. In the latter, however, an increase of the rate of selfcorrosion with the increase of external anodic current is assumed.

The investigation of assuring the presence of the self-corrosion would give a clue for the determinations concerning which one of these two theories is acceptable. The presence of self-corrosion can be ascertained by determining the local cell polarization curve which is related to the steady surface condition under a flow of external anodic current. Such polarization curve could be obtained by the rapid polarization method which was recently completed by the present authors. ${ }^{(4)}$

2. Experimental : Six kinds of aluminum specimens, the components of which are summarized in Table, 1 , were polished with a $0 / 3$ emery paper, degreased with benzene and etched in fresh $10 \% \mathrm{NaOH}$ and $5 \%$ $\mathrm{HNO}_{3}$ solution succesively. The dissolution rate and the hydrogen evolution rate of these $\mathrm{Al}$ specimens were measured in the buffer solution
Table 1 Composition and Treatment of Specimen

\begin{tabular}{|c|c|c|c|c|c|c|c|c|}
\hline \multirow{2}{*}{ Specimen } & \multicolumn{7}{|c|}{ Composition } & \multirow{2}{*}{ Treatment } \\
\hline & A1 & $\mathrm{Si}$ & $\mathrm{Fe}$ & $\mathrm{Cu}$ & Mn & $\mathbf{M g}$ & $\mathrm{Cr}$ & \\
\hline Pure Al & 99.997 & 0.002 & 0.001 & trace & e - & 一 & - & $\begin{array}{c}\text { Annealed for } 2 \mathrm{hrs} \text {. } \\
\text { at } 300^{\circ} \mathrm{C}\end{array}$ \\
\hline $2 \mathrm{~S}$ & 99.73 & 0.12 & 0.13 & 0.02 & - & - & - & $\begin{array}{c}\text { Annealed for } 2 \mathrm{hrs} \text {. } \\
\text { at } 300^{\circ} \mathrm{C}\end{array}$ \\
\hline $3 \mathrm{~S}$ & 98.12 & 0.24 & 0.25 & 0.1 & 1.22 & - & - & $\begin{array}{c}\text { Annealed for } 2 \mathrm{hrs} \text {. } \\
\text { at } 300^{\circ} \mathrm{C}\end{array}$ \\
\hline $3 \mathrm{~S}-1 / 2 \mathrm{H}$ & 98.8 & - & - & - & 1.2 & - & - & Cold worked \\
\hline $52 \mathrm{~S}-1 / 2 \mathrm{H}$ & 97.25 & - & - & - & - & 2.5 & 0.25 & Cold worked \\
\hline $61 \mathrm{~S}-\mathrm{T}_{4}$ & 97.9 & 0.6 & & 0.25 & - & 1.0 & 0.25 & Quenched from $520^{\circ} \mathrm{C}$ \\
\hline
\end{tabular}

containing $7.3 \mathrm{~g}$ of $\mathrm{NaCl}, 3.6 \mathrm{~g}$ of $\mathrm{HCl}$ and $10 \mathrm{~g}$ of $\mathrm{NaC}_{2} \mathrm{H}_{3} \mathrm{O}_{2}$ per litre under the conditions of steady anodic current, Iext.

Moreover, the polarization characteristics in the same medium was measured by, the following special technique, namely rapid method : the time variation of the electrode potential with the inspantaneous change of current from the Iext to I was recorded by means of an electromagnetic oscillograph or a cathode ray oscilloscope, the value of potential $\mathrm{E}$ established immediately after the change of current was determined by extrapolating the potential-time curve to zero time, and the values of $\mathrm{E}$ against $\log \mathrm{I}$ was plotted. The circuit employed for this measurement of polarization characteristics is shown in Fig. 1.

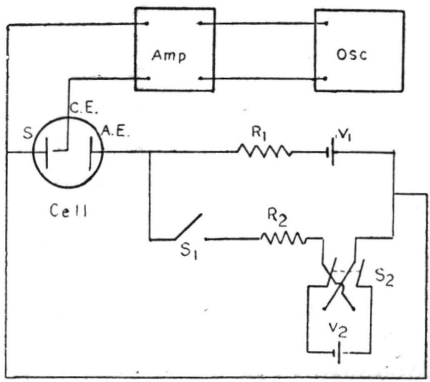

S : Specimen AE : Auxiliary electrode $\mathrm{CE}$ : $\mathrm{KCl}$-saturated calomel electrode $\mathrm{V}_{1}, \mathrm{~V}_{2}$ : DC source $\quad \mathrm{R}_{1}, \mathrm{R}_{2}$ : Resistor $\mathrm{S}_{1}, \mathrm{~S}_{2}$ : Switch Amp : Amplifier

Osc: Cathode ray oscilloscope or electromagnetic oscillograph

Fig. 1 Electrical circuit for measurement of polarization characteristics.

* Department of Applied Chemistry, Faculty of Engineering of Hokkaido University, Hokkaido.

The original written in Japanese can be seen in J. Electrochem. Soc. Japan, 27, 437 (1959). 
3. Results : It was found that the rate of dissolution determined by the colorimetric analysis of solution always exceeded that expected by Faraday's law, and that this excess rate was in good agreement with the rate of hydrogen evolution, as shown as in Fig 2 and Fig 3.

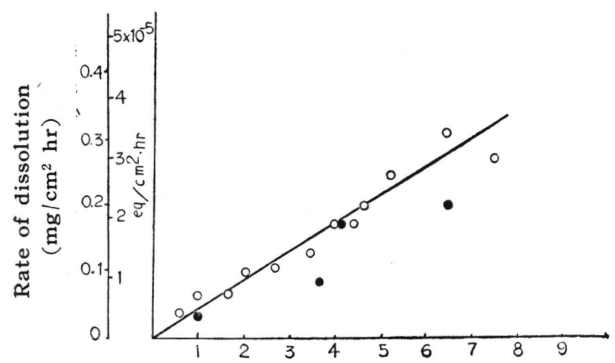

Current density $\left(\mathrm{mA} / \mathrm{cm}^{2}\right)$ Iext -.. Pure aluminum 0 Specimen $3 \mathrm{~S}$

Fig. 2 Relationship between the excess dissolution rate and current density.

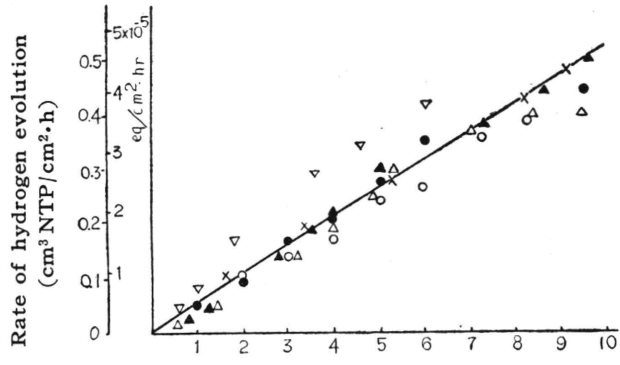

Current density $\left(\mathrm{mA} / \mathrm{cm}^{2}\right)$ Iext

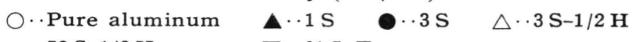$$
\times \cdots 52 \mathrm{~S}-1 / 2 \mathrm{H} \quad \nabla \cdot 61 \mathrm{~S}-\mathrm{T}_{4}
$$

Fig. 3 Relation between the rate of hydrogen evolution and current density.

The anodic and cathodic polarization curves of specimen $3 \mathrm{~S}$, which were determined for the steady conditions established under various magnitude of anodic current Iext, such as $0,0.43,1.18,4.0$ and $10.0 \mathrm{~mA} / \mathrm{cm}^{2}$, are shown in Fig 4 as an example. These polarization curves show a Tafel's relation in the range of relatively higher current density compared with the preliminary steady anodic current, Iext. The intersection obtained by extrapolating the anodic and cathodic Tafel's lines related to the respective surface condition agreed fairly well with the spontaneous potential, i.e. about $-0.85 \sim-1.00$ volt $v s$. S.C.E., which was measured immediately after switching the current Iext off. Therefore, it can be assumed that these Tafel lines represent the local cell polarization curve related to the respective given surface condition. Dissimilar polarization curves were also obtained in the case of other specimens.

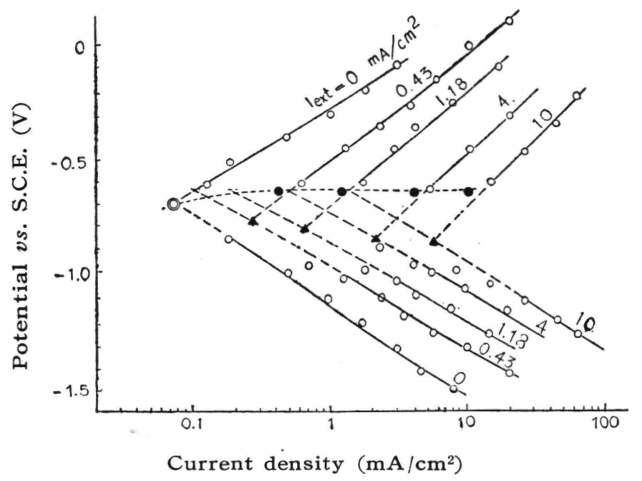

Fig. 4 Polarization curves of specimen $3 \mathrm{~S}$ measured by rapid method.

4. Discussion: If the local cathodic and anodic currents, $i_{c}$ and $i_{a}$, are determined by extrapolating the cathodic and anodic Tafel lines to the steady anodic potential, f.e. $-0,65 \mathrm{~V} v s$. S.C.E., the magnitude of current $i_{c}$ or $\left(i_{a}-\mathrm{Iext}\right)$ will be equivalent to the rate of self-corrosion. Actually, the rate of self-corrosion estimated by this method is in good agreement with the observed rate of excess dissolution and hydrogen evolution, as shown in Fig 5.

Consequently, it became evident that the anomalous dissolution phenomenon of $\mathrm{Al}$ anode, at least under the above-mentioned experimental condition, resulted from the increase of the rate of selfcorrosion with increasing anodic current. At that time, it is not required to assume the formation 


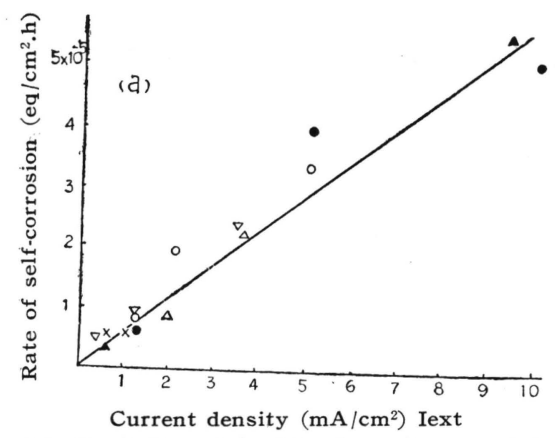

(a) From the value of local anodic current $i_{a}$

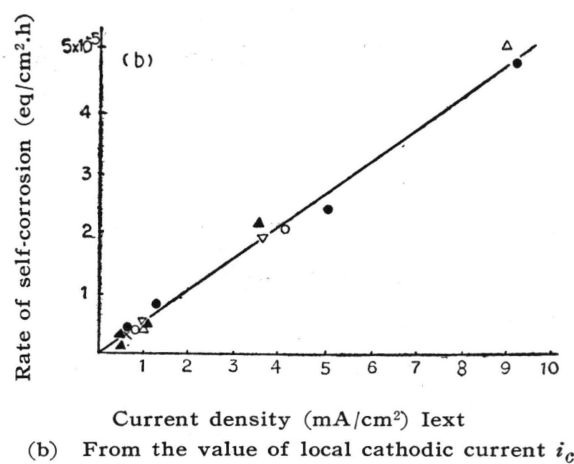

(b) From the value of local cathodic current $i_{c}$

Fig. 5 Rate of self-corrosion estimated by analysis of polarization curves.

of mono-valent $\mathrm{Al}$ ion. Moreover, it was confirmed that the stimulating effect of $\mathrm{KBrO}_{3}$ to the anomalous dissolution can be also attributed to the increase of rate of self-corrosion by the depolarization effect of local cathodic reaction by this agent.

Finally, it is suggested that the cause of increasing rate of self corrosion with anodic current will be presumably due to the breakdown of protective oxide film accompanying the creation of both anodic and cathodic active areas on the inner surface of pits.

(Received June 2, 1959)

\section{Literature :}

(1) A.W. Davidson, F. Jirik, J.A.C.S. 72, 1700 (1950), W.F. Bennett, A.W. Davidson, J. Kleinberg, ibid. 74, 732 (1952) ; M.D. Rausch, W.E. McEwen, J. Kleinberg, ibid. 77, 2093 (1955).

(2) N.O. Tomashov, V.N. Modestova, Trud. Inst. Fiz. Khim. Akad. Nauk. SSSR, Issledoraniya po Korrozii Metal, 1, 42 (1951).

(3) W. Blum, H.S. Rawdon, Trans. Am. Electrochem. Soc. 52, 408 (1927).

(4) G. Okamoto, M. Nagayama, N. Sato, Proc. 8 th C.I.T.C.E., 72 (1956), This journal, 25, 166 (1957). 